\title{
CARACTERÍSTICAS DOS SISTEMAS DE CUSTOS GERENCIAIS DE SUBSIDIÁRIAS ALEMÃS OPERANDO NO BRASIL: UMA ANÁLISE SOB A PERSPECTIVA DO ISOMORFISMO E DO DECOUPLING
}

\section{CHARACTERISTICS OF THE MANAGEMENT COSTS SYSTEMS OF GERMAN SUBSIDIARIES OPERATING IN BRAZIL: AN ANALYSIS FROM THE PERSPECTIVE OF ISOMORPHISM AND DECOUPLING}

\section{CARACTERÍSTICAS DE LOS SISTEMAS DE COSTOS GERENCIALES DE SUBSIDIARIAS ALEMANAS OPERANDO EN BRASIL: UN ANÁLISIS DESDE LA PERSPECTIVA DEL ISOMORFISMO Y DEL DECOUPLING}

Recebido em: 04-06-2018

Avaliado em: 22-04-2019

Reformulado em: 21-05-2019

Aceito para publicação em: 13-03-2020

Publicado em: 02-09-2020

Editor Responsável: Franciele Beck

\section{Rodrigo Paiva Souza ${ }^{1}$}

Leticia Damo Ferreira Ramalho ${ }^{2}$

Reinaldo Guerreiro ${ }^{3}$

\section{RESUMO}

Este trabalho investigou práticas de gerenciamento de custos em subsidiárias de empresas alemãs operando no Brasil, com objetivo de avaliar a ocorrência de pressões isomórficas (coercitivas, miméticas e normativas) e o nível de decoupling nessas organizações. As pressões isomórficas tencionam para a uniformização de práticas, enquanto que o decoupling diz respeito ao uso apenas cerimonial dessas práticas. O método empregado foi o survey, sendo coletadas 27 respostas de gestores de subsidiárias alemãs de grande e médio porte que operam no Brasil. Os resultados trazem evidências de que há uma forte associação entre as práticas da subsidiária e da matriz, revelando elementos de pressão isomórfica coercitiva e mimética, já as pressões isomórficas normativas se mostraram menos marcantes. O nível de decoupling encontrado entre matriz e subsidiária foi baixo. $\mathrm{O}$ estudo contribui para a literatura e prática de gestão de custos, indicando que as pressões isomórficas da matriz contribuem para redução dissociação de práticas de contabilidade e gerenciamento de custos entre filial e matriz (decoupling).

Palavras-chave: Sistemas de Custos Gerenciais; Pressões Isomórficas; Decoupling.

\section{ABSTRACT}

This work investigated cost management practices in subsidiaries of German companies operating in Brazil, in order to evaluate the incidence of isomorphic pressures (coercive, mimetic and normative)

\footnotetext{
${ }^{1}$ Doutor em Controladoria e Contabilidade pela Universidade de São Paulo (USP); Professor de Contabilidade na Faculdade FIPECAFI; E-mail: rodrigo.souza@fipecafi.org

${ }^{2}$ Mestre em Controladoria e Contabilidade pela Universidade de São Paulo (USP); Professora do Centro Universitário Paulista. E-mail: leticia.ramalho@usp.br

${ }^{3}$ Doutor em Controladoria e Contabilidade pela Universidade de São Paulo (USP); Professor de Contabilidade na Universidade de São Paulo (USP); E-mail: reiguerr@usp.br
} 
and the level of decoupling in these organizations. The isomorphic pressures are intended to standardize practices, while decoupling refers to the ceremonial use of these practices. The method used was the survey, and 27 responses were collected from managers of large and medium-sized German subsidiaries operating in Brazil. The results provide evidence that there is a strong association between the practices of the subsidiary and the parent company, revealing elements of coercive and mimetic isomorphic pressure, normative isomorphic pressures were found but in lower level. The level of decoupling found between matrix and subsidiary was low. This study contributes to literature and cost management practice indicating that the isomorphic pressures of the parent company contribute to reduce the dissociation of accounting and costly management practices between subsidiary and parent company (decoupling).

Keywords: Management Costs Systems; Isomorphic Pressures; Decoupling.

\section{RESUMEN}

Este trabajo investigó prácticas de gestión de costos en subsidiarias de empresas alemanas operando en Brasil, con el objetivo de evaluar la ocurrencia presiones isomórficas (coercitivas, miméticas y normativas) y el nivel de decoupling en esas organizaciones. Las presiones isomórficas se proponen estandarizar prácticas, mientras que el decoupling se refiere al uso ceremonial de esas prácticas. El método empleado fue el survey, siendo recogidas 27 respuestas de gestores de subsidiarias alemanas de grande y mediano porte que operan en Brasil. Los resultados proyectan evidencias de una fuerte asociación entre las prácticas de la subsidiaria y de la matriz, revelando elementos de presión isomórfica coercitiva y mimética, las presiones isomórficas normativas se mostraron menos evidentes. El nivel de decoupling encontrado entre matriz y subsidiaria fue bajo. El estudio contribuye a la literatura y práctica de gestión de costos indicando que las presiones isomórficas de la matriz contribuyen a reducir la disociación de prácticas de contabilidad y gerencialmente de costos entre la filial y la matriz.

Palabras-clave: Sistemas de Costos Gerenciales; Presiones Isomórficas; Decoupling.

\section{INTRODUÇÃO}

As empresas alemãs operando no Brasil representam em torno de $10 \%$ do Produto Interno Bruto (PIB) industrial brasileiro, sendo considerado o maior parque de empresas alemãs fora da Alemanha, segundo a Câmara do Comércio e Indústria Brasil-Alemanha (2019). Muito embora a Alemanha tenha uma grande importância no desenvolvimento de sistemas gerenciais de controle de custos (Krumwiede, 1998; Krumwiede, \& Suessmair, 2008; Kajüter, \& Schröder, 2013), há poucos estudos sobre sistemas de custos de empresas alemãs operando no Brasil.

Diversas pesquisas na área de contabilidade gerencial apontam para a convergência internacional de práticas gerenciais (Shields, 1998; Van Der Stede, 2003), com evidências empíricas de que subsidiárias de empresas multinacionais adotam práticas originadas na matriz mesmo quando estas se mostram ineficientes (Portz, \& Lere, 2010).

Evidências empíricas demonstram que os sistemas gerenciais de custos adotados em empresas sob a influência germânica são detalhados e possuem alto nível de sofisticação (Kajüter, \& Schröder, 2013). Como exemplo, o método de análise por margem de contribuição (conhecido em alemão pela sigla GPK) é amplamente difundido nas empresas alemãs (Kajüter, 2005; Portz, \& Lere, 2010; Kajüter, \& Schröder, 2013), contudo também há evidências de que subsidiárias dessas multinacionais optem por práticas locais de gerenciamento de custos.

As empresas subsidiárias presentes em nação diferente do seu país de origem enfrentam o dilema de adotar sistemas corporativos de gerenciamento e apuração de custos, considerando as pressões institucionais isomórficas estabelecidas pela matriz (Endenich, Brandau, \& Hoffjan, 2011) 
ou, por outro lado, implementar práticas locais em atenção às suas próprias necessidades (Kellermanns, \& Islam, 2004; Portz, \& Lere, 2010).

Considerando a importância das empresas alemãs para a economia nacional e a carência de estudos específicos na literatura brasileira sobre práticas adotadas no sistema de custos gerenciais em subsidiárias de empresas alemãs que operam no Brasil, uma das motivações do presente estudo é conhecer a estrutura do sistema de custos dessas empresas, avaliada sob quatro aspectos: (i) os métodos de custeio para decisões, (ii) ferramentas de gestão; (iii) objetivos do sistema de custos gerencial; e (iv) suporte de sistema integrado de informações (ERP). O conhecimento dessa estrutura dos sistemas de custos gerenciais é importante para que se possa entender a sua complexidade e desempenho (Kajüter, \& Schröder, 2013).

Além disso, a compreensão das práticas do sistema de custos gerencial pode ser ampliada quando analisada sob a ótica da teoria institucional, especificamente pela identificação de pressões isomórficas de convergência, de natureza coercitiva, normativa e mimética, e pela análise do fenômeno da dissociação entre práticas da matriz e da filial, conhecido como "decoupling” (Meyer, \& Rowan, 1977; Moll, Burns, \& Major, 2006; Callado et al., 2014).

Nesse contexto, a questão de pesquisa que direcionou o desenvolvimento do presente estudo foi: Quais as características institucionais identificadas na estrutura do sistema de custos gerenciais em subsidiárias de empresas alemãs que operam no Brasil? O objetivo da pesquisa foi a identificação das pressões institucionais associadas ao sistema de contabilidade de custos gerenciais de subsidiárias de empresas alemãs que operam no Brasil (Sulaiman, Ahmad, \& Alwi, 2004; Guerreiro, Pereira, \& Frezatti, 2006).

A análise pressões institucionais foi desenvolvida considerando duas perspectivas. A primeira perspectiva considera as pressões isomórficas (coercitivas, miméticas e normativas) de convergência e a segunda foca o decoupling das práticas do sistema de custos gerenciais adotadas pela subsidiária versus as práticas utilizadas pela matriz. $\mathrm{O}$ método de pesquisa utilizado foi o survey, por meio do qual foram coletados dados de um conjunto de subsidiárias de empresas alemãs de grande e médio porte, dos setores automobilístico e de máquinas e equipamentos. Os dados coletados foram analisados com utilização de técnicas de estatística descritiva e análise de associações.

O trabalho apresenta contribuições para o conhecimento da área contábil considerando os três aspectos investigados, ou seja, o estudo sobre a estrutura do sistema de custos gerenciais em empresas alemãs operando no Brasil, a análise das pressões isomórficas de convergência associadas a estas práticas e a verificação da ocorrência do decoupling no âmbito do relacionamento subsidiária e matriz.

Os resultados da pesquisa também podem contribuir para profissionais de empresas alemãs que operam no Brasil para uma autoavaliação de sua lógica de gerenciamento de custos, conforme proposto por Cruz, Major e Scapens (2009) em comparação a outras subsidiárias, bem como para executivos da sede alemã, que podem se beneficiar do conhecimento sobre o nível de dissociação de práticas (decoupling) em subsidiárias brasileiras, que deverá ser monitorado na matriz.

O trabalho está estruturado em cinco seções, incluindo esta introdução. A seção dois apresenta a fundamentação teórica da pesquisa, a seção três descreve os procedimentos metodológicos utilizados, a seção quatro apresenta e discute os principais achados do estudo e a seção cinco reporta as conclusões e considerações finais da pesquisa.

\section{REVISÃO DE LITERATURA}

Nesta revisão são apresentados os estudos que fundamentam a estrutura dos sistemas de custos gerenciais, os fatores de pressão isomórfica e o conceito de decoupling. 


\subsection{Estudos sobre sistemas de custos gerenciais}

O sistema de custos gerenciais é parte fundamental do sistema de contabilidade gerencial e tem sido objeto de várias pesquisas nacionais e internacionais. A pesquisa realizada por Souza, Lisboa e Rocha (2003) mapeou práticas gerenciais em uso em 49 empresas multinacionais de grande porte operantes no Brasil, e demonstrou que $73 \%$ utilizam o método de custeio por absorção para tomada de decisão e o custo padrão é utilizado por $83,7 \%$ dessas empresas, além disso, em $100 \%$ das empresas, o orçamento é empregado como forma de controle de custos e reporte à matriz.

Ono e Robles Junior (2004) entrevistaram profissionais de empresas de médio e grande porte, e também professores do Estado de Santa Catarina, com objetivo de verificar se há condições para aplicação do custeio alvo (target costing) nas empresas da região. Esses autores constataram que o ambiente não é favorável à adoção desse método, especialmente em razão do desconhecimento da técnica tanto por profissionais quanto por professores.

Reginato e Guerreiro (2011) realizaram investigação em 45 indústrias brasileiras de grande porte e apresentaram resultados congruentes com os de Souza, Lisboa e Rocha (2003), destacando que o método de custeio por absorção e o custo padrão são amplamente implementados, enquanto que o custeio por atividade e custeio alvo ainda não são utilizados de forma intensa pelas empresas pesquisadas. Souza, Silva e Pilz (2010) complementam que a preferência por métodos de gestão de custos tradicionais se dá em função da não identificação objetiva dos benefícios de métodos de gestão de custos contemporâneos como o custeio baseado em atividades (ABC) e o custeio alvo.

O trabalho de Guerreiro, Cornachione Júnior e Soutes (2011) investigou o uso de artefatos de contabilidade gerencial em amostra de empresas de grande porte operando no Brasil, visando atingir dois objetivos: o primeiro, avaliar se empresas brasileiras de grande porte utilizam artefatos modernos de Contabilidade Gerencial e, o segundo, verificar se as empresas que se destacam pela qualidade de suas informações aos usuários externos também se destacam pela maior utilização de artefatos modernos de Contabilidade Gerencial de apoio a usuários internos. Os resultados do estudo demonstram que as empresas da amostra utilizam artefatos modernos de Contabilidade Gerencial e que a amostra de empresas que se destacam pelo padrão de suas publicações, não se diferencia, em termos de utilização de artefatos modernos de Contabilidade Gerencial, do grupo das demais empresas pesquisadas.

Russo e Guerreiro (2017) investigaram as práticas de contabilidade gerencial em amostra de 102 organizações não financeiras de grande porte operando no Brasil, buscando entender a percepção de gestores sobre a sociomaterialidade dessas práticas, com base na lógica institucional cerimonial (uso baseado em ritos) versus a instrumental (uso baseado na solução de problemas). O estudo identificou que dependendo de forças isomórficas e de difusão que atuam sobre as práticas, elas são levadas a assumir comportamento cerimonial (5\%), instrumental (61\%) ou misto (26\%).

Com relação aos estudos internacionais, Hughes e Gjerde (2003) investigaram uma amostra de 130 empresas americanas e constataram que, embora o método de custeio por atividades $\mathrm{ABC}$ seja muito discutido no meio acadêmico, o seu nível de implementação é relativamente baixo.

Estudos como o de Major e Hopper (2005) e Gosselin (2006) apresentam interessante debate sobre a evolução e a utilização efetiva do método de custeio por atividades. O paradoxo é que, por um lado, os gestores reconhecem os benefícios do $\mathrm{ABC}$, mas, por outro lado, o nível de implementação é bastante baixo.

Krumwiede e Suessmair (2008) realizaram estudo com 286 empresas localizadas na Alemanha, Áustria e Suíça. Os resultados indicam que o método do custeio variável é empregado por $56 \%$ do total de empresas participantes da amostra, sendo que $25 \%$ delas aplicam ainda o custeio por atividades $\mathrm{ABC}$ e $40 \%$ utilizam análise por meio do sistema de custeio alemão de margem de contribuição (GPK).

Kajüter e Schröder (2013), pesquisando empresas americanas instaladas na Alemanha e empresas alemãs com características semelhantes como grupo de controle, concluem que $63 \%$ das 
subsidiárias americanas possuem sistema de custos menos complexo que empresas alemãs e que $85,5 \%$ das subsidiárias seguem ao menos uma imposição da matriz sobre os sistemas de custos gerenciais.

Considerando o escopo da pesquisa - características do sistema de custos gerenciais analisou-se a utilização das práticas de gerenciamento de custos mais consolidadas conforme pesquisas anteriores, combinando práticas tradicionais e contemporâneas, assim como práticas especialmente difundidas na Alemanha. Dessa forma, foi definido, para o presente trabalho, o estudo de quatro dimensões do sistema de custos gerenciais, tendo como inspiração as obras apresentadas no Quadro 1:

Quadro 1 - Dimensões de análise do sistema de custos gerenciais

\begin{tabular}{|c|c|c|}
\hline $\begin{array}{c}\text { Dimensões do Sistema de } \\
\text { Custos Gerencial }\end{array}$ & Descrição & Referências \\
\hline Métodos de custeio & $\begin{array}{l}\text { (a) por absorção, } \\
\text { (b) custeio variável e } \\
\text { (c) custeio baseado em atividades }\end{array}$ & $\begin{array}{l}\text { Souza, Lisboa, \& Rocha, 2003; Frezatti, 2005; } \\
\text { Friedl, Küpper, \& Pedell, 2005; Major, \& Hopper, } \\
\text { 2005; Gosselin, 2006; Wegmann, \& Nozile, 2009; } \\
\text { Reginato, \& Guerreiro, 2011; Guerreiro, } \\
\text { Cornachione Jr., \& Soutes, 2011. }\end{array}$ \\
\hline $\begin{array}{l}\text { Ferramentas de gestão de } \\
\text { custos }\end{array}$ & $\begin{array}{l}\text { (a) custo padrão, } \\
\text { (b) custeio alvo, } \\
\text { (c) margem de contribuição e } \\
\text { orçamentos }\end{array}$ & $\begin{array}{l}\text { Souza, Lisboa, \& Rocha, 2003; Kajüter, 2005; } \\
\text { Atkinson, Kaplan, \& Young, 2010; Guerreiro, } \\
\text { Cornachione Jr., \& Soutes, } 2011 .\end{array}$ \\
\hline $\begin{array}{l}\text { Objetivos do sistema de } \\
\text { custos }\end{array}$ & $\begin{array}{l}\text { (a) redução de custos, } \\
\text { (b) melhoria de processos, } \\
\text { (c) formação de preço de venda, } \\
\text { (d) melhorias de processos }\end{array}$ & Kajüter, 2005; Kajüter, \& Schröder, 2013. \\
\hline $\begin{array}{l}\text { Suporte do ERP ( } \text { software) } \\
\text { ao sistema de custos } \\
\text { gerencial }\end{array}$ & $\begin{array}{l}\text { (a) suporte à operação, } \\
\text { (b) suporte fiscal, } \\
\text { (c) integração com a matriz, } \\
\text { (d) uso de software complementar }\end{array}$ & $\begin{array}{l}\text { Brandau et al., 2013, Krumwiede, \& Suessmair, } \\
2008 .\end{array}$ \\
\hline
\end{tabular}

Fonte: elaborado pelos autores.

\subsection{Pressões isomórficas de convergência}

A teoria institucional investiga o impacto de regras, normas sociais e conceitos racionais nas estruturas formais das organizações, em suas práticas e procedimentos (Meyer, \& Rowan, 1977; Scott, 2008), demonstrando que as decisões não são sempre racionais, mas buscam alcançar legitimidade. Neste contexto, de acordo com Dimaggio e Powell (1983), as organizações operam dentro de uma certa "uniformidade" para buscar legitimidade de suas práticas de negócio. Esses autores identificaram três fatores chaves que conduzem essa busca por uniformidade, conhecidos como fatores de pressão isomórfica: a pressão coercitiva, a normativa e a mimética. As pressões isomórficas institucionais de convergência levariam subsidiárias a adotar os mesmos modelos gerenciais de sua matriz, mesmo quando tais modelos não fossem eficientes (Meyer, \& Rowan, 1977; Scott, 2008; Portz, \& Lere, 2010).

A busca por legitimidade é apontada como a essência da Teoria Institucional (Carruthers, 1995). Meyer e Rowan (1977) destacam que as organizações buscam aumentar sua legitimidade por meio da implementação de práticas institucionalizadas na sociedade, sendo o isomorfismo uma das formas adotadas pelas empresas a fim de alcançar legitimidade.

O isomorfismo coercitivo é descrito por Scott (2008) como a pressão formal exercida por instituições governamentais, instituições internacionais ou que emerge de forças sociais. Organizações estariam sujeitas a pressões coercitivas quando dependem de recursos escassos, como capital, clientes e fornecedores e pode-se afirmar o mesmo para relações entre matriz e subsidiárias (Mizruchi, \& Fein, 1999). 
Salancik e Pfeffer (1978) realizaram uma pesquisa sob a perspectiva de recursos escassos e investigaram a influência de uma organização sobre o desenho corporativo de outras que são dependentes de seus recursos. Conforme os autores, essa perspectiva é especialmente importante, pois fornece argumentos indicativos de que a pressão coercitiva não é apenas exercida pela legislação internacional (Björkman, Fey, \& Park, 2007), mas também por detentores de recursos escassos (Mizruchi, \& Fein, 1999; Brandau et al., 2013). Essa noção pode ser transposta para a relação entre matriz e subsidiária, justamente o ambiente de pesquisa do presente trabalho.

Beuren, Fachini e Nascimento (2010) estudaram a presença de isomorfismo nas práticas de controladoria de empresas familiares do ramo têxtil de Santa Catarina. O estudo concluiu que existe evidências de isomorfismo nas práticas estudadas, não sendo detalhadas as formas de isomorfismo.

O trabalho de Barbosa, Wanderley e Soeiro (2017) teve como objetivo analisar o processo de institucionalização dos mecanismos de controle gerencial implementados no gerenciamento do relacionamento com empresas terceirizadas. O estudo de caso foi realizado em uma empresa do setor de energia elétrica. Os resultados destacam que devido aos valores e crenças institucionalizados, a forma de contratação de seus prestadores de serviços continuou seguindo os mesmos moldes do setor público, mesmo após a privatização da empresa. Constatou-se que, paulatinamente, a empresa vem modificando a forma de contratação e instituindo novas formas de avaliação e acompanhamento de fornecedores. Observou-se, ainda, um isomorfismo entre as práticas e procedimentos da empresa estudada e empresas terceirizadas.

Brandau et al. (2013), em pesquisa realizada com empresas brasileiras e alemãs, constataram que a pressão coercitiva foi o elemento indutor para a adoção do padrão das normas contábeis International Financial Reporting Standards (IFRS) no Brasil. A pesquisa de Souza, Lisboa e Rocha (2003), realizada com multinacionais brasileiras, constatou que 79,6\% das empresas possuíam seu método de custeio determinado pela matriz, evidenciando indícios de pressão coercitiva.

As pressões miméticas podem ocorrer devido à adoção e disseminação de melhores práticas (benchmarking) (Dimaggio, \& Powell, 1983; Haveman, 1993), integrando o pilar cognitivo-social e sendo encontradas como crenças comuns ou lógicas de ação compartilhadas (Scott, 2001). O isomorfismo mimético faz referência à cópia (Dimaggio, \& Powell, 1983) e, de acordo com Brown (2011), ocorre quando corporações adotam práticas bem sucedidas que foram disseminadas por organismos reconhecidos pelo seu conhecimento na área. Brandau et al. (2013) destacam que o isomorfismo mimético tem feito empresas brasileiras e alemãs adotarem ferramentas de gestão similares.

As empresas brasileiras ressaltam a importância do benchmarking e algumas percebem esse processo como oportunidade, outras como uma necessidade (Fonseca, \& Machado-da-Silva, 2018). A visão alemã atribui ao benchmarking um importante fator de convergência das práticas gerenciais contábeis. Outro indício atribuído ao isomorfismo mimético é a ampla adoção do mesmo sistema integrado (ERP) pelas empresas.

Brown (2011) e Haveman (1993) ressaltam que, em pesquisas realizadas no campo da teoria institucional, verifica-se a caracterização do isomorfismo mimético pela mentalidade "siga o líder", pensamento observado em programas de remuneração, estrutura corporativa e programa de corte de gastos.

Em pesquisa realizada com 27 empresas brasileiras, Oyadomari et al. (2008) analisaram quais fatores influenciavam as empresas a adotar novas ferramentas de controle gerencial. Segundo os autores, o isomorfismo mimético foi o fator mais relevante na amostra. Conforme Dimaggio e Powell (1983), consultorias também são responsáveis pela difusão de novas práticas de gestão e pelo isomorfismo mimético.

Por fim, as pressões normativas são atribuídas principalmente ao profissionalismo e à criação de padrões nas redes de relacionamento. Dimaggio e Powell (1983, p. 152) definem profissionalização como "o ajuntamento coletivo de membros de uma ocupação para definir condições e métodos para seus trabalhos". Scott (2001) apresenta, como indicadores para o pilar 
normativo, certificação e acreditação. Para esses autores, universidades e treinamentos profissionais são importantes fontes do isomorfismo. Brandau et al. (2013) encontraram, por meio de entrevistas com gestores, que o isomorfismo normativo nas empresas acontece através da crescente formação profissional de seus gestores e por treinamentos em padrões internacionais.

\subsection{Decoupling}

O fenômeno oposto ao isomorfismo é denominado decoupling, ou seja, representa a dissociação entre as práticas reais da empresa e a imagem formal dela perante a matriz, ligada à técnica e às regras (Meyer, \& Rowan, 1977; Moll, Burns, \& Major, 2006). O conceito de decoupling guarda semelhança com o conceito de desinstitucionalização de práticas (Rezende, Guerreiro, \& Dalmácio, 2012).

Carruthers (1995) observa que estudos em contabilidade sobre a perspectiva da Nova Sociologia Institucional (NIS) utilizam o conceito de decoupling como uma resposta organizacional à pressão externa para implementar novas rotinas contábeis. A estrutura formal da organização está ligada à sua apresentação ao mundo exterior, mas não à maneira como as coisas de fato acontecem, ou seja, ao uso apenas cerimonial e não instrumental das práticas. A ausência de aderência entre o que é divulgado e o que é efetivamente utilizado no dia a dia das organizações é denominada decoupling (ou dissociação).

Meyer e Rowan (1977), citados por Siti-Nabiha e Scapens (2005), mencionam que sistemas adotados para assegurar a legitimidade de instituições externas podem tornar-se dissociados dos sistemas internos. No Brasil, Guerreiro e Souza (2015) questionaram 113 indivíduos e observaram dissociação entre gestores intermediários e alta gestão sobre a importância percebida de atividades do processo de gestão organizacional.

Para Scott (2001), além de uma resposta a pressões externas, a dissociação faz parte do processo de estabilidade e alteração, e as questões da mudança e da dissociação são de natureza empírica. $\mathrm{O}$ autor considera ainda que mudanças ocorridas a partir de processos impositivos nos quais a autoridade é exercida como, por exemplo, no relacionamento matriz-subsidiária, fazem com que a dissociação esteja propensa a ser menor, pois tais mudanças são mais profundas (Scott, 2001).

Conforme Meyer e Rowan (1977), citados por Marques (2012, p. 85), “as organizações se adaptam às mudanças ambientais (especialmente em ambientes altamente institucionalizados) adotando determinados mitos institucionalizados, mas podendo responder com o decoupling quando a nova estrutura adotada não condisser com os requisitos de eficiência”. É possível, desse modo, reconhecer que as organizações têm a habilidade de responder às demandas externas por legitimidade, porém sem afetar seus mecanismos internos. Assim, a organização seria capaz de responder as pressões externas por adoção de novas técnicas contábeis e por manter a eficiência técnica interna de suas operações.

Utilizando o construto teórico fornecido pela NIS, autores como Meyer e Rowan (1977) e Scott (2008) constatam que a separação entre imagem externa, estruturas e procedimentos internos pode ocorrer intencionalmente ou não. Conforme Siti-Nabiha e Scapens (2005), o decoupling pode ainda ser analisado por três diferentes óticas: (a) há simples dicotomia entre instituição e sistemas técnicos; (b) o técnico pode realmente ser dissociado do institucional; (c) existe um tratamento simplista do papel exercido pelo poder e pela política (Perrow, Meyer, \& Scott, 1983).

O decoupling pode ocorrer porque a subsidiária apresenta resistência a mudanças (SitiNabiha, \& Scapens, 2005), especialmente no caso de fusões e aquisições, devido a diferentes lógicas de gerenciamento (Cruz, Major, \& Scapens, 2009), resultado da propagação de regras de procedimentos inerentes à cultura ou ainda visando à obtenção de legitimidade (Carruthers, 1995).

A presente pesquisa adota o conceito de decoupling apresentado por Meyer e Rowan (1977), de que a estrutura formal das organizações, com sua aparência altamente racional, é dissociada da sua prática organizacional, ou seja, a subsidiária pode utilizar ferramentas de gestão por solicitação da matriz (uso cerimonial), sem efetivamente incorporá-las como prática efetiva para tomada de 
decisões. Emprega-se tal definição por se considerar que ela reflete melhor o relacionamento entre matriz e subsidiária.

\section{PROCEDIMENTOS METODOLÓGICOS}

O método de pesquisa empregado foi o survey. Embora essa técnica apresente algumas desvantagens, sobretudo no que se refere a dificultar um maior aprofundamento sobre a compreensão de fenômenos complexos (Smith, 2003), mesmo seus críticos mais severos reconhecem o poder das opiniões coletivas e consideram, como suas maiores vantagens, a alta validade externa e a possibilidade de coleta de dados de grandes populações (Van Der Stede, Young, \& Chen, 2005).

A presente pesquisa investigou o isomorfismo nas três formas apresentadas: coercitiva, mimética e normativa. O isomorfismo coercitivo na relação matriz-subsidiária foi analisado por meio da coerção do método de custeio, ferramentas de gestão e ERP (software de gestão) utilizados para tomada de decisão. Para identificar o isomorfismo mimético, foi pesquisada a presença de consultorias na empresa com finalidade de implementação de novas técnicas, assim como a utilização do mesmo ERP que seus pares/concorrentes. O isomorfismo na forma normativa foi investigado considerando a formação acadêmica no exterior dos profissionais respondentes, a utilização de treinamentos unificados, bem como a presença de expatriados na área de controladoria e contabilidade da subsidiária.

\subsection{População alvo}

Tendo em vista o interesse da pesquisa, foi selecionada a população de subsidiárias alemãs operantes no Brasil dos ramos automobilísticos e de máquinas e equipamentos, por serem segmentos com sistemas de custos sofisticados (Kajüter, \& Schröder, 2013).

Bruns e Waterhouse (1975) sugerem que a sofisticação em contabilidade gerencial também está diretamente ligada ao tamanho da empresa. Guerreiro e Rocha (2010), bem como Cohen, Kaimenaki e Zorgios (2007), mencionam que apenas em indústrias se pode encontrar a aplicação de determinadas ferramentas contábeis de gestão. Dessa maneira, a população delimitada para esta pesquisa foi de grandes e médias empresas industriais.

Para ter acesso às empresas objeto de estudo, foi utilizada a lista de associados na Câmara de Comércio Brasil-Alemanha dos setores automobilístico e de máquinas e equipamentos. Observamos que a escolha da nacionalidade e dos segmentos da amostra têm como justificativa a importância de empresas alemãs no cenário industrial brasileiro, a longa tradição alemã em contabilidade de custos e a premissa de que estudos que concentram a investigação em segmentos específicos ganham em maior homogeneidade e foco de análise.

O cadastro inicial relacionava 273 empresas de ambos os ramos de atividades. No primeiro momento, o controller ou o responsável pelo sistema de custos gerencial de todas as empresas listadas foram contatados por telefone e convidados a participar da pesquisa. Neste primeiro contato, 119 empresas foram eliminadas por não serem, de fato, subsidiárias de empresas alemãs e outras 17 organizações também foram excluídas porque estavam repetidas na lista por serem empresas do mesmo grupo econômico e possuírem as mesmas características. Sendo assim, a população alvo da pesquisa, considerando os dois setores, foi de 137 empresas.

\subsection{Instrumento de pesquisa}

Após extensa revisão bibliográfica, foi desenvolvido um questionário contendo 32 perguntas para capturar caraterísticas das empresas, dos respondentes e do sistema de custos gerencial, bem como a ocorrência de pressões isomórficas e do decoupling. Inicialmente o instrumento foi submetido à análise e revisão por acadêmicos da área de controladoria e contabilidade, em que foram propostos ajustes e correções. Em um segundo momento, foi realizado um pré-teste por dois profissionais da área de controladoria e contabilidade de empresa alemã de grande porte e, após novos ajustes, foi 
enviado novamente a um grupo de quatro acadêmicos da área de controladoria para revisão final. Todo o processo de validação aparente do instrumento de pesquisa teve duração de dois meses.

O instrumento foi desenvolvido em plataforma eletrônica para acesso online da população alvo por meio do software QUESTBACK EFS 10.9. As questões foram distribuídas em cinco seções, conforme a estrutura a seguir:

- Seção I: 8 questões com o objetivo de traçar um perfil do respondente e da empresa;

- Seção II: 7 questões para determinar o método de custeio empregado para decisões e quais os objetivos do sistema de custos gerencial;

- Seção III: 8 questões sobre planejamento e controle de custos, com objetivo de identificar quais as ferramentas utilizadas no planejamento e controle de custos;

- Seção IV: 7 questões sobre características gerais do sistema e da área de gerenciamento de custos, com o objetivo de captar a presença de pressões isomórficas e do decoupling;

- Seção V: 2 questões sobre objetivos e desempenho do sistema de custos gerencial, com a finalidade de verificar divergência entre as determinações da matriz e da gestão local.

O questionário poderá ser solicitado aos autores sempre que se fizer necessário.

\subsection{Coleta dos dados e características dos respondentes}

Para coletar as respostas foi enviado um primeiro e-mail convite, contendo link para acessar o questionário (lembrando que todos já haviam sido contatados por telefone na etapa de validação da amostra). Após 15 dias do envio do primeiro e-mail, foi realizado novo contato telefônico com os potenciais participantes e um novo e-mail convite foi encaminhado. Após 30 dias do envio do primeiro e-mail, os potenciais participantes receberam lembretes via rede social (LinkedIn) e receberam o último e-mail com convite para participação da pesquisa. Todo o processo de coleta dos dados teve duração de dois meses. Foi realizado teste de média das respostas recebidas após o primeiro, segundo e terceiro $e$-mails e não foi identificada diferença significativa.

Ao final do processo de coleta foram recebidas 27 respostas válidas, correspondendo a uma taxa de resposta de $19,71 \%$. É possível afirmar que as empresas respondentes refletem as características da população alvo, ou seja, ser subsidiária de empresa alemã, de grande porte e com operações consolidadas no Brasil.

Os profissionais que responderam o questionário são todos brasileiros, declararam manter contato regular e frequente com a matriz e $81 \%$ estão a, no máximo, dois níveis hierárquicos do executivo principal da empresa no Brasil, sendo que $26 \%$ possuem formação acadêmica principal ou complementar no exterior.

\subsection{Tratamento dos dados coletados}

A amostra é não probabilística, obtida por acessibilidade, sendo assumido que apresenta representatividade. Em linha com a amostra obtida, as análises foram efetuadas por meio de técnicas de estatística descritiva com objetivo de melhor compreender o comportamento dos dados através de tabelas, gráficos e medidas resumo (Fávero et al., 2009).

Para classificação do nível de isomorfismo de cada empresa foi desenvolvido um sistema de pontuação. No que se refere a pressão coercitiva a pontuação máxima estabelecida foi de 6 pontos. Já para identificar o nível de isomorfismo mimético a pontuação máxima estabelecida foi de 4 pontos e, finalmente, para identificação do nível de isomorfismo normativo a pontuação máxima foi de 3 pontos. Para a mensuração do nível de decoupling foi estabelecido um sistema de pontuação de no máximo 9 pontos. A explicação mais detalhada sobre o sistema de atribuição dos pontos para mensurar o nível de isomorfismo e decoupling das práticas de gerenciamento de custos é apresentada nas seções 4.2 e 4.3 . 


\section{APRESENTAÇÃO E DISCUSSÃO DOS RESULTADOS}

Nesta seção os resultados são apresentados e analisados com os seguintes desdobramentos: mapeamento das características do sistema de custos gerenciais, identificação de pressões isomórficas, análise do decoupling de práticas de custos gerenciais entre a matriz e a subsidiária e análise da relação entre as pressões isomórficas e o nível de decoupling.

\subsection{Características do Sistema de Custos Gerenciais}

Neste tópico são apresentados os resultados dos quatro grupos de características do sistema de custos gerenciais das empresas da amostra, ou seja, (i) método de custeio utilizado, (ii) ferramentas de gerenciamento de custos, (iii) principais objetivos do sistema de gerenciamento de custos e (iv) tipo de suporte provido pelo software ERP.

\subsubsection{Método de Custeio}

A Tabela 1 apresenta o percentual de utilização dos diferentes métodos de custeio pelas empresas da amostra para tomada de decisão local (TDL) e para atendimento à matriz (Matriz).

Tabela 1 - Utilização do método de custeio para tomada de decisões

\begin{tabular}{lcc}
\hline & TDL & Matriz \\
\hline Custeio por Absorção & $77 \%$ & $74 \%$ \\
Custeio Variável & $33 \%$ & $26 \%$ \\
Custeio ABC & $15 \%$ & $15 \%$ \\
\hline
\end{tabular}

Fonte: elaborada pelos autores.

Com relação aos métodos de custeio, as respostas dos gestores permitem observar que o método de custeio empregado para TDL e o método de reporte à matriz são equivalentes. Segundo Dorminey et al. (2012), é possível inferir a ocorrência de pressão isomórfica na forma coercitiva quando agentes da matriz, em posição privilegiada, determinam qual o método de reporte que os gestores locais devem utilizar para TDL. O resultado aponta que o método de custeio por absorção é utilizado tanto para reporte à matriz quanto para TDL, sendo indício de ocorrência de pressão isomórfica coercitiva para determinar o método de custeio para TDL.

O custeio por absorção foi indicado por $77 \%$ das empresas como sendo o método utilizado para TDL. Pesquisas internacionais, tais como a de Hughes e Gjerde (2003), apontam níveis semelhantes de utilização. A pesquisa de Souza, Lisboa e Rocha (2003), analisando multinacionais operando no Brasil, relatou que $65 \%$ das empresas pesquisadas utilizam o custeio por absorção para TDL, ou seja, pesquisas também fornecem subsídios para inferir a ocorrência de pressão isomórfica mimética, uma vez que a prática do mercado é utilizar o custeio absorção para TDL.

Embora o custeio por absorção parcial (aqui analisado) não considere a alocação dos gastos administrativos, de vendas e encargos financeiros, $59 \%$ das empresas pesquisadas que declararam utilizar o custeio por absorção para TDL, declararam também alocar estes gastos aos produtos para fins de análise gerencial. Esse procedimento está em linha com a filosofia de custeio alemã, revelando outro indício de pressão isomórfica coercitiva.

No que diz respeito ao método de custeio variável, 33\% das subsidiárias da amostra indicaram que utilizam esse método de custeio para TDL. Outras pesquisas demonstram resultados diferentes conforme países e tipo de amostras investigadas. A pesquisa de Hughes e Gjerde (2003) indica que $26 \%$ da amostra de empresas americanas utilizam esse método de custeio, enquanto que a pesquisa de Krumwiede e Suessmair (2008) aponta um grau de utilização de 56\% entre empresas alemãs.

Pesquisas anteriores no Brasil chegaram a apontar uma taxa de utilização do custeio variável de $62 \%$ em empresas de grande porte (Reginato, \& Guerreiro, 2011), mas a pesquisa de Souza, Lisboa e Rocha (2003) encontrou uma taxa de utilização do custeio variável em apenas $20 \%$ de 
multinacionais de grande porte instaladas no Brasil, mais aderente aos resultados da presente pesquisa. No custeio variável foi observado o maior desvio entre a utilização para TDL e reporte à matriz, indicando que este método é mais utilizado localmente do que para reporte.

O método de custeio baseado em atividades é utilizado por $15 \%$ das empresas pesquisadas. A pesquisa de Hughes e Gjerde (2003) indica que 38\% da amostra de empresas americanas utilizam esse método de custeio. A pesquisa de Krumwiede e Suessmair (2008), em amostra de empresas alemãs, aponta um grau de utilização de 25\%. Sulaiman, Ahmad e Alwi (2004) indicam a baixa utilização do custeio ABC em empresas operando em países da Ásia (2\% na China, 20\% na Índia, $28 \%$ na Malásia). No Brasil, Reginato e Guerreiro (2011) encontraram taxa de utilização do ABC em $64 \%$ das empresas de grande porte, o que diverge bastante dos resultados encontrados no presente estudo.

\subsubsection{Ferramentas de Gerenciamento de Custos}

A Tabela 2 apresenta o percentual de utilização de ferramentas de gerenciamento de custos para tomada de decisões locais (TDL) e o percentual de utilização pela matriz.

Tabela 2 - Ferramentas de gerenciamento de custos

\begin{tabular}{llc}
\hline & TDL & Matriz \\
\hline Custo Padrão & $63 \%$ & $48 \%$ \\
Custeio Alvo & $52 \%$ & $45 \%$ \\
Margem de Contribuição & $52 \%$ & $48 \%$ \\
Orçamento & $96 \%$ & $93 \%$ \\
\hline
\end{tabular}

Fonte: elaborada pelos autores.

Ferramentas de gestão de custos, além de serem consideradas como parte integrante das características do sistema gerencial de custos, também são fontes de análises para constatação do isomorfismo e decoupling.

Esta pesquisa investigou diversos aspectos da utilização do custo padrão pelas empresas da amostra. Os dados demonstram que o custo padrão é utilizado por $63 \%$ das empresas pesquisadas para decisões locais e que $48 \%$ da amostra também utiliza a ferramenta para reporte à matriz. Considerada como uma ferramenta tradicional para controle dos custos, esse índice de utilização está abaixo de outras amostras de empresas pesquisadas, tais como a pesquisa de Souza, Lisboa e Rocha (2003), que apresentou o percentual de $83,7 \%$.

Dentro do universo de subsidiárias que declararam utilizar o custo padrão, praticamente todas calculam o custo padrão para os elementos de custo de matéria-prima, mão de obra direta e despesas gerais da fábrica. Deve ser observado que $41 \%$ das empresas empregam o custo padrão também para controle das despesas administrativas e comerciais.

A pesquisa também buscou analisar se a ferramenta de custo padrão está institucionalizada nas empresas, ou seja, se o seu uso não é apenas cerimonial (Russo, \& Guerreiro, 2017). Para isso foi questionada a frequência do acompanhamento entre o custo padrão e o custo incorrido. Ficou evidenciado que, apenas em 12\% das empresas da amostra, o uso do custo padrão é apenas cerimonial, uma vez que as empresas declararam não acompanhar o desvio entre o custo planejado e o realizado ou acompanhar apenas anualmente.

O custeio alvo é considerado uma ferramenta contemporânea de gestão de custos, sendo o conhecimento a seu respeito consolidado pela maioria das empresas (Sulaiman, Ahmad, \& Alwi, 2004). Das subsidiárias pesquisadas, $52 \%$ declararam utilizar o custeio alvo e, no que diz respeito ao grau de importância dessa ferramenta, $86 \%$ das empresas usuárias afirmaram que o custeio alvo é uma ferramenta essencial para gerenciamento de custos.

Na pesquisa realizada por Souza, Lisboa e Rocha (2003), nenhuma das empresas da amostra declarou utilizar essa ferramenta. No estudo de Kajüter (2005), em universo de empresas alemãs, 
$55 \%$ declararam utilizar essa metodologia. Na pesquisa conduzida por Guilding, Cravens e Tayles (2000), em amostra de empresas do Reino Unido, Nova Zelândia e Estados Unidos, o custeio alvo aparece entre as mais adotadas.

No que diz respeito ao questionamento se a aplicação do custeio alvo a produtos novos é realizada por solicitação da matriz, $21 \%$ das empresas declaram que sim, e $15 \%$ das empresas afirmaram também utilizar esta informação para o processo de TDL.

A análise de margem de contribuição é uma das características mais marcantes da contabilidade de custos alemã (Krumwiede, \& Suessmair, 2008). Deve ser observado que o modelo alemão de custos trabalha com diferentes conceitos de margem de contribuição. Os resultados revelaram que $52 \%$ das empresas da amostra declararam adotar a análise de margem de contribuição regularmente, sendo que, dentro deste percentual de utilização, 50\% calculam a margem no nível II ou mais.

Friedl, Küpper e Pedell (2005) destacam que parte da popularização deste método é explicada pelo fato de o ERP da empresa alemã SAP utilizar a lógica de análise de margem de contribuição no módulo de custos de seu software. Observa-se que 57\% das empresas que declaram utilizar análise de margem de contribuição utilizam o SAP como software de gestão.

Os resultados evidenciam que o orçamento é uma ferramenta quase unânime entre as subsidiárias para TDL, $96 \%$ realizam orçamento anual. Este resultado está em linha com os achados de Russo e Guerreiro (2017) sobre o uso instrumental versus o uso cerimonial da prática de gestão mais utilizada pelas empresas. Similar resultado havia sido encontrado na pesquisa de Souza, Lisboa e Rocha (2003) que reportaram a utilização desse artefato gerencial por todas as empresas da amostra estudada.

No que diz respeito ao uso da prática gerencial do orçamento, os resultados indicam que a empresa matriz, quase em sua totalidade, monitora de maneira frequente os desvios que ocorrem entre o custo planejado e o custo realizado. Esse resultado está em linha com os achados de Russo e Guerreiro (2017), indicando a forte utilização instrumental do orçamento. Nesse sentido, pode-se inferir que ocorre pressão isomórfica coercitiva, segundo a descrição de Scott (2008) e Mizruchi e Fein (1999), que se caracteriza por uma pressão formal exercida por instituições que estão socialmente em situações mais privilegiadas.

\subsubsection{Principais Objetivos do Sistema de Custos Gerenciais}

A Tabela 3 apresenta os resultados relativos aos objetivos do sistema de custos gerenciais. Foi pesquisada a aderência dos sistemas de custos ao atendimento de quatro objetivos definidos, sob a ótica da tomada de decisão local e quanto ao atendimento à matriz:

Tabela 3 - Principais objetivos do Sistema de Custos Gerenciais

\begin{tabular}{lcc}
\hline & TDL & Matriz \\
\hline Facilitar formação de preço & $92 \%$ & $70 \%$ \\
Fomentar melhoria processos & $92 \%$ & $70 \%$ \\
Aumento da transparência & $92 \%$ & $81 \%$ \\
Redução de custos & $100 \%$ & $89 \%$ \\
\hline
\end{tabular}

Fonte: elaborada pelos autores.

Pode ser observado que o sistema de custos gerenciais das empresas da amostra está muito aderente com os quatro objetivos definidos principalmente no que diz respeito a TDL. Os objetivos do sistema, sob a ótica de atender a matriz, segundo os respondentes, não possuem o mesmo nível de importância.

Por exemplo, $100 \%$ das subsidiárias apontaram a redução de custos como principal objetivo do sistema para TDL, porém $89 \%$ das empresas matriz veem a redução de custos como um objetivo principal. Para $92 \%$ das empresas, o sistema de custos gerenciais colabora no processo de formação de preços e no fomento a melhorias de processos no contexto da TDL, por outro lado, apenas $70 \%$ 
dos respondentes entendem que esses objetivos são importantes para o atendimento das necessidades da matriz.

Kajüter (2005) pesquisou os objetivos do sistema de custos gerenciais de empresas alemãs e constatou que a redução de custos e o aumento da transparência são os objetivos principais do sistema na amostra estudada.

\subsubsection{Suporte Provido Pelo ERP}

A Tabela 4 apresenta os resultados desta pesquisa no que diz respeito aos quatro tipos de suporte definidos, que o software ERP proporciona ao sistema de custos gerenciais, sob a perspectiva específica do atendimento às necessidades da subsidiária (TDL):

Tabela 4 - Suporte do ERP ao Sistema de Custos Gerenciais

\begin{tabular}{lc}
\hline & TDL \\
\hline Suporte à operação & $63 \%$ \\
Suporte fiscal & $85 \%$ \\
Integração com a matriz & $44 \%$ \\
Uso de software complementar & $100 \%$ \\
\hline
\end{tabular}

Fonte: elaborada pelos autores.

Nos diversos estudos analisados, o item ERP não é visto como uma característica do sistema de custos gerenciais, contudo Krumwiede (1998) destaca a importância fundamental do software ERP na difusão de características dos métodos de custeio. Nesse sentido, por exemplo, pode ser observado o emprego do custo padrão pela quase totalidade de softwares ERP, ou ainda o cálculo de margens de contribuição no software da SAP.

Nesta pesquisa, foi considerado que o software ERP desempenha um papel fundamental na implementação dos sistemas de custos gerenciais. O software alemão SAP obteve maior taxa de utilização (41\%) da amostra, resultado em linha com o universo de empresas alemãs pesquisadas, enquanto o software ERP da TOTVS é utilizado por 22\% das empresas.

O ERP é apontado por Brandau et al. (2013) como uma das principais evidências do isomorfismo mimético. SAP e TOTVS estão presentes em $63 \%$ das subsidiárias estudadas e metade das empresas que utilizam o ERP da SAP respondeu acreditar que as outras empresas do mesmo ramo utilizavam os mesmos softwares.

Das empresas investigadas, 63\% consideram eficiente o suporte provido pelo ERP para as operações da empresa. Este número sobe para $85 \%$ quando é questionado sobre o suporte dado para cumprir com obrigações fiscais e tributárias. É interessante observar ainda que em $100 \%$ das subsidiárias é necessário o uso de software complementar (Excel, por exemplo) para gerir e planejar os custos.

\subsection{Pressões Institucionais Isomórficas}

Esta seção busca identificar e refletir sobre a existência de pressões institucionais isomórficas de convergência nas formas coercitiva, mimética e normativa. O isomorfismo coercitivo é analisado considerando-se os seguintes elementos: (i) método de custeio, (ii) ferramentas de gestão e (iii) software ERP utilizado. $O$ isomorfismo mimético é analisado considerando-se os seguintes elementos: (i) presença de consultorias, (ii) utilização do mesmo ERP do mercado e (iii) utilização das mesmas ferramentas de gestão que o mercado emprega. $\mathrm{O}$ isomorfismo normativo foi estudado à luz dos seguintes elementos: (i) formação no exterior, (ii) treinamentos unificados e (iii) presença de expatriados. 


\subsubsection{Pressão isomórfica coercitiva}

Considerando as pesquisas desenvolvidas por Salancik e Pfeffer (1978) e DiMaggio e Powell (1983), é possível afirmar que o isomorfismo em sua forma coercitiva é operacionalizado através de três formas ou construtos: pela influência exercida por fornecedores, pelos clientes e pela empresa matriz. De acordo com Meyer e Rowan (1977), Scott (2008) e Portz e Lere (2010), as pressões isomórficas institucionais de convergência levariam subsidiárias a adotar os mesmos modelos gerenciais de sua matriz, mesmo quando tais modelos não fossem eficientes. Esta pesquisa foca o relacionamento isomórfico coercitivo entre a matriz e sua empresa subsidiária no exterior.

Para a análise do nível de pressão isomórfica em sua forma coercitiva, esta pesquisa desenvolveu a construção de um sistema de pontuação refletindo as evidências de isomorfismo coercitivo identificadas no âmbito do sistema de custos gerenciais das empresas subsidiárias. $\mathrm{O}$ primeiro elemento desta análise é o método de custeio utilizado pelas empresas para TDL. Foram analisados os três métodos de custeio pesquisados sob a ótica da tomada de decisões (custeio por absorção, custeio variável e custeio baseado em atividades). De acordo com o critério pré-definido, as subsidiárias que adotam pelo menos um método de custeio proposto pela matriz receberam 1 ponto neste quesito.

O segundo elemento de análise é a ferramenta de gestão para TDL, sendo analisada a utilização do custo padrão, do custeio alvo, da margem de contribuição e do orçamento. De acordo com o critério estabelecido, as empresas receberam 1 ponto para cada ferramenta utilizada por indução da matriz. Assim, cada empresa pode ter no máximo 4 pontos.

Finalmente, o terceiro elemento de análise se refere ao software ERP utilizado pela empresa subsidiária. Pelo critério definido nesta pesquisa, as empresas que utilizam software determinado pela matriz receberam 1 ponto.

A pontuação máxima de cada empresa pode ser 6 pontos. Foi definido que o intervalo entre 5 e 6 pontos corresponde a um nível alto de isomorfismo coercitivo, o intervalo entre 3 e 4,9 corresponde a um nível médio de coerção e entre 1 e 2,9 corresponde a um nível baixo de isomorfismo coercitivo. O isomorfismo coercitivo foi encontrado em $100 \%$ das empresas pesquisadas, porém em diferentes níveis. Os resultados demonstram que 52\% das empresas da amostra apresentam um alto nível de isomorfismo coercitivo, $41 \%$ da amostra apresentam médio nível e $7 \%$ das empresas demonstram baixo nível. A média da amostra é 4,35 e o desvio padrão 1,3. Esses resultados demonstram que há evidências da presença de pressões isomórficas em sua forma coercitiva no sistema de custos gerenciais de empresas alemãs operando no Brasil. Esse resultado corrobora com os achados de Brandau et al. (2013) e Souza, Lisboa e Rocha (2003) sobre a presença de pressões isomórficas coercitivas nas empresas brasileiras.

As informações sobre as características dos sistemas de custos gerenciais apresentadas na seção 4.1 permitem reflexões complementares sobre o aspecto do isomorfismo coercitivo na relação matriz x subsidiária. O exame analítico dos resultados demonstra que 100\% das subsidiárias adotam pelo menos um dos métodos de custeio para TDL por imposição da matriz. Os resultados evidenciam ainda que $89 \%$ das empresas declaram que um dos papéis centrais das ferramentas do sistema de custos gerenciais é atender as demandas da matriz e 74\% reconhecem que a empresa matriz realiza um acompanhamento frequente dos custos e do desempenho orçamentário da subsidiária. No que diz respeito ao software ERP, 44\% dos respondentes afirmaram manter uma integração com o software da matriz e ainda deve ser observado que o software alemão SAP é utilizado por $41 \%$ das empresas da amostra.

\subsubsection{Pressão isomórfica mimética}

O isomorfismo em sua forma mimética é considerado como uma tendência das empresas em adotar as mesmas práticas que outras empresas do mercado utilizam (Dimaggio, \& Powell, 1983; Carruthers, 1995; SCOTT, 2008). Haveman (1993) e Brown (2011) destacam que, em pesquisas 
realizadas sobre a teoria institucional, se verifica a caracterização do isomorfismo mimético pela mentalidade "siga o líder". A pesquisa conduzida por Brandau et al. (2013) considerou o uso do mesmo ERP das demais empresas do próprio ramo de atividade como um fator de mimetismo. Autores como Dimaggio e Powell (1983), Carruthers (1995), Scott (2008) e Brandau et al. (2013) consideram que o mimetismo acontece também por meio da difusão de práticas gerenciais bemsucedidas por meio de consultorias.

Para Brandau et al. (2013), o isomorfismo mimético tem levado empresas brasileiras e alemãs a adotarem ferramentas de gestão parecidas, algumas delas importadas do mundo anglo-fônico, como indicadores baseados em fluxo de caixa e em receita residual. Neste trabalho, o isomorfismo mimético é analisado com base na perspectiva das empresas subsidiárias e seus concorrentes (pares), ou seja, empresas que atuam no mesmo ramo de atividade e mesmo local (país). Desta forma, três elementos foram considerados para mensurar o isomorfismo em sua forma mimética: a presença de consultorias, a utilização do mesmo ERP que outras empresas do mercado e a utilização das mesmas ferramentas de gerenciamento de custos que outras empresas do mercado.

Foi construído um sistema de pontuação para avaliar o nível de mimetismo a partir da atribuição de pontos para os elementos considerados como evidências do isomorfismo mimético. A pontuação máxima possível é 4, obtida no caso de a subsidiária utilizar o custo padrão e o orçamento (2 pontos), trabalhar com o software ERP da SAP ou da TOTVs (1 ponto), e que a área de gerenciamento e controle de custos tenha tido contrato de consultoria nos últimos 5 anos (1 ponto).

Os resultados revelam que em $56 \%$ das subsidiárias está presente um alto nível de mimetismo (notas 3 e 4), um percentual de $37 \%$ das subsidiárias apresentaram nível médio de mimetismo (nota 2) e apenas 7\% demonstram baixo nível de mimetismo (notas 0 e 1). Conforme Haveman (1993) e Brown (2011), a internalização de práticas adotadas pelo mercado com maior frequência é o principal aspecto observado na pressão isomórfica mimética.

Esses resultados estão em linha com os achados de Callado e Pinho (2014), que investigaram práticas de gestão de custos entre micro e pequenas empresas que atuam no setor comercial e no setor de prestação de serviços em busca de evidências de isomorfismo mimético. Os resultados obtidos apresentam evidências estatísticas significativas sobre semelhanças acerca das práticas referentes à gestão de custos indicando a presença de isomorfismo mimético entre elas. O ensaio desenvolvido por Oyadomari et al. (2008) por meio da análise dos principais autores em Teoria Institucional na vertente NIS, tendo como foco a reflexão crítica sobre a teoria e o processo de institucionalização do VBM, concluiu que a institucionalização da VBM sustentou-se fortemente no pilar cognitivo-cultural, com utilização do mecanismo mimético.

No contexto do estudo realizado, é possível inferir que, na amostra estudada, determinadas práticas e instrumentos do sistema de custos gerenciais são utilizados em função das pressões isomórficas miméticas. As empresas são do mesmo país de origem (Alemanha), atuam no mesmo local (Brasil) e pertencem ao mesmo ramo de atividade (automobilístico e máquinas e equipamentos). Dessa amostra de empresas, 44\% contrataram serviços de consultoria nos últimos 5 anos, 63\% utilizam apenas duas marcas de software ERP, 63\% utilizam o custo padrão e $96 \%$ das empresas fazem uso do orçamento anual.

\subsubsection{Pressão isomórfica normativa}

Conforme mencionado na revisão da literatura, as pressões normativas são atribuídas principalmente ao profissionalismo e à criação de padrões nas redes de relacionamento. A profissionalização se caracteriza como o ajuntamento coletivo de membros de uma ocupação para definir condições e métodos para seus trabalhos (Dimaggio, \& Powell, 1983). Os indicadores clássicos do pilar normativo são a certificação e a acreditação (Scott, 2001). Nesse contexto, universidades e treinamentos profissionais são importantes fontes do isomorfismo.

Em linha com Scott (2001), a pressão isomórfica no pilar normativo foi investigada através de elementos que evidenciam aspectos de formação, acreditação e de certificação de profissionais da 
área de controladoria e contabilidade. Assim, foram considerados três elementos: (i) formação no exterior dos executivos que fizeram parte desta pesquisa, (ii) treinamento corporativo de funcionários e (iii) presença de expatriados no departamento de controladoria/financeiro. Com base em questões sobre esses elementos foi construído o sistema de pontuação de, no máximo, 3 pontos.

Os resultados mostram que $7 \%$ das empresas da amostra apresentaram os 3 elementos indicativos do isomorfismo normativo, $41 \%$ da amostra demonstraram 2 elementos e 52\% apresentaram um elemento ou nenhum (41\% apenas um e $11 \%$ nenhum). Logo é possível afirmar que o isomorfismo em sua forma normativa apresenta nível baixo nas empresas da amostra, porém foi evidenciado, em algum grau, em $89 \%$ das subsidiárias.

De um ponto de vista mais analítico, observa-se que $78 \%$ das empresas pesquisadas possuem alguma certificação ou acreditação e, segundo Scott (2001), este é um dos indicadores do isomorfismo normativo. Outro indicativo desse tipo de pressão isomórfica normativa, apontado por Endenich, Brandau e Hoffjan (2011), é a presença recente (últimos dois anos) de expatriados na área de contabilidade e controladoria em $41 \%$ das subsidiárias. Nesse sentido, embora a metodologia adotada nesta pesquisa (baseada em Dimaggio e Powell, 1983, e Scott, 2001) aponte para um baixo nível de isomorfismo normativo, há evidências da presença de elementos de isomorfismo normativo nas organizações pesquisadas.

\subsection{Análise do Decoupling}

O último foco de análise institucional foi a verificação da existência de decoupling (dissociação) das práticas de gerenciamento de custo entre as ações para satisfazer requerimentos da empresa matriz e as práticas para TDL.

O decoupling é considerado uma resposta a pressões externas sofridas pelas organizações para a aderência de novas normas ou procedimentos. Quando estes não são compatíveis com os níveis internos de eficiência, pode ocorrer o decoupling, ou seja, o procedimento é praticado na empresa, porém não faz parte da rotina do processo decisório local (Meyer, \& Rowan, 1977; Yazdifar et al., 2008; Marques, 2012).

O decoupling do sistema de custos gerenciais foi mensurado pela não aderência da administração local às práticas de reporte requeridas pela matriz. A não aderência das práticas foi questionada considerando três elementos da estrutura do sistema de custos gerenciais: métodos de custeio, ferramentas de gerenciamento de custos e o sistema ERP.

O critério de pontuação do nível de decoupling desenvolvido na pesquisa tem o máximo de 9 pontos. A dissociação entre os métodos de custeio utilizados para TDL e reportados para a matriz representa, no máximo, 3 pontos. A dissociação entre as ferramentas de gerenciamento de custos utilizadas para TDL e aquelas reportadas para a matriz correspondem a, no máximo, 4 pontos. Finalmente, a dissociação proporcionada pelo sistema ERP corresponde a 2 pontos, sendo analisada sob o prisma do suporte à operação e do suporte ao cumprimento das obrigações fiscais.

Os instrumentos requeriam respostas que correspondessem às práticas utilizadas para a TDL e para reporte à matriz. Sempre que o respondente indicou que não havia conformidade entre essas práticas, esta não conformidade foi considerada um evento de decoupling e atribuído 1 ponto na mensuração do nível de decoupling.

Scott (2001) considera que, em casos da presença do isomorfismo em sua forma coercitiva, o decoupling tende a ser reduzido. Os resultados da presente pesquisa estão em linha com as considerações de Scott (2001), pois, como demonstrado anteriormente, o nível de isomorfismo coercitivo foi considerado alto, enquanto que os resultados sobre o nível de decoupling revelaram que 97\% da amostra apresentaram pontuação de zero a três e a média da amostra foi de 1,1 pontos (pontuação máxima possível de 9 pontos). 


\subsection{Análise de relações entre características isomórficas e o nível de decoupling}

Neste tópico, com base nos achados apresentados em seções anteriores deste trabalho, são efetuadas análises descritivas complementares, envolvendo o relacionamento entre características do sistema de custos gerenciais e o nível de decoupling.

A primeira análise desenvolvida, demonstrada na Figura 1, verifica a relação entre o isomorfismo em sua forma coercitiva e o nível de decoupling apresentado pela subsidiária no que diz respeito ao uso das práticas do sistema impostas pela matriz.

Figura 1 - Nível de pressão coercitiva x nível de decoupling

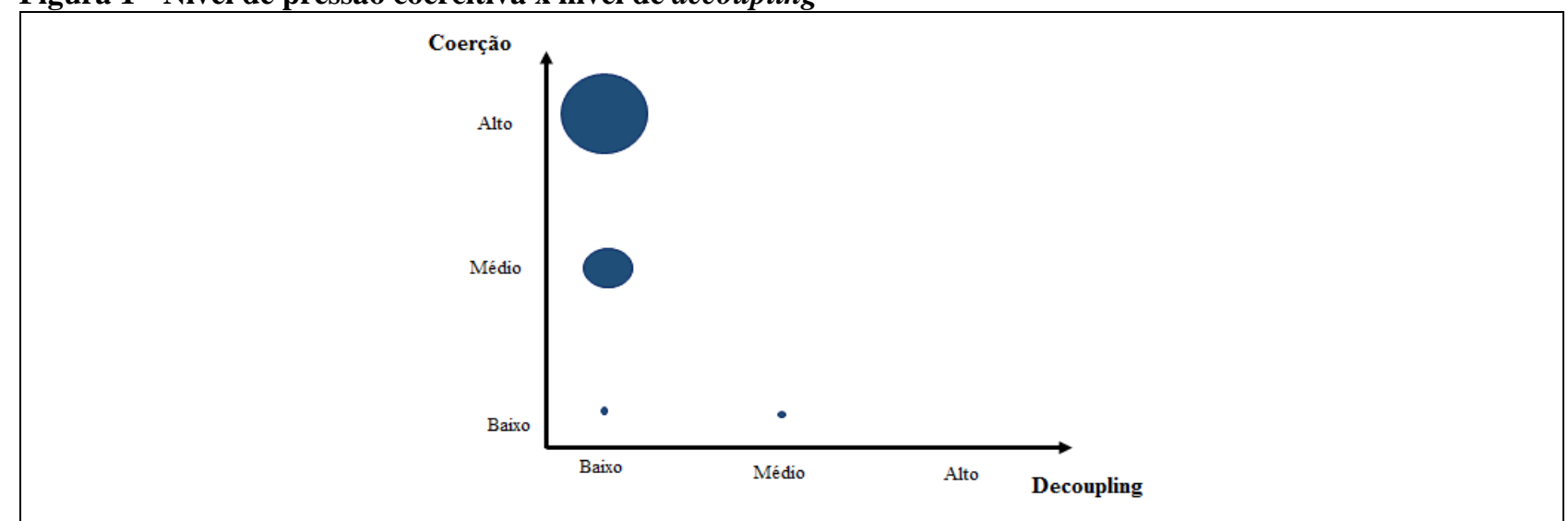

Fonte: elaborada pelos autores.

É possível visualizar que o alto nível de pressão isomórfica em sua forma coercitiva está relacionado a baixo nível de decoupling, corroborando com Scott (2001). Os dados demonstram que $52 \%$ das empresas da amostra indicam a combinação, baixo decoupling e alta pressão coercitiva, enquanto $41 \%$ das empresas possuem baixo decoupling e média pressão coercitiva, e $7 \%$ apresentam baixa pressão coercitiva a um nível baixo/médio de decoupling. Os resultados sugerem que forte pressão coercitiva reduz a dissociação de práticas gerenciais.

A segunda análise busca averiguar se há relação entre a divergência dos objetivos do sistema de custos gerenciais e o nível de decoupling. A pressuposição inicial que orientou essa análise é que, quanto menor o grau de divergência dos objetivos do sistema de custos para TDL e aqueles determinados pela matriz, menor o nível de decoupling das práticas do sistema. A Figura 2 evidencia a relação entre o nível de divergência dos objetivos do sistema de custos gerencial e o nível de decoupling.

Figura 2 - Divergência de objetivos do SCG x nível de decoupling

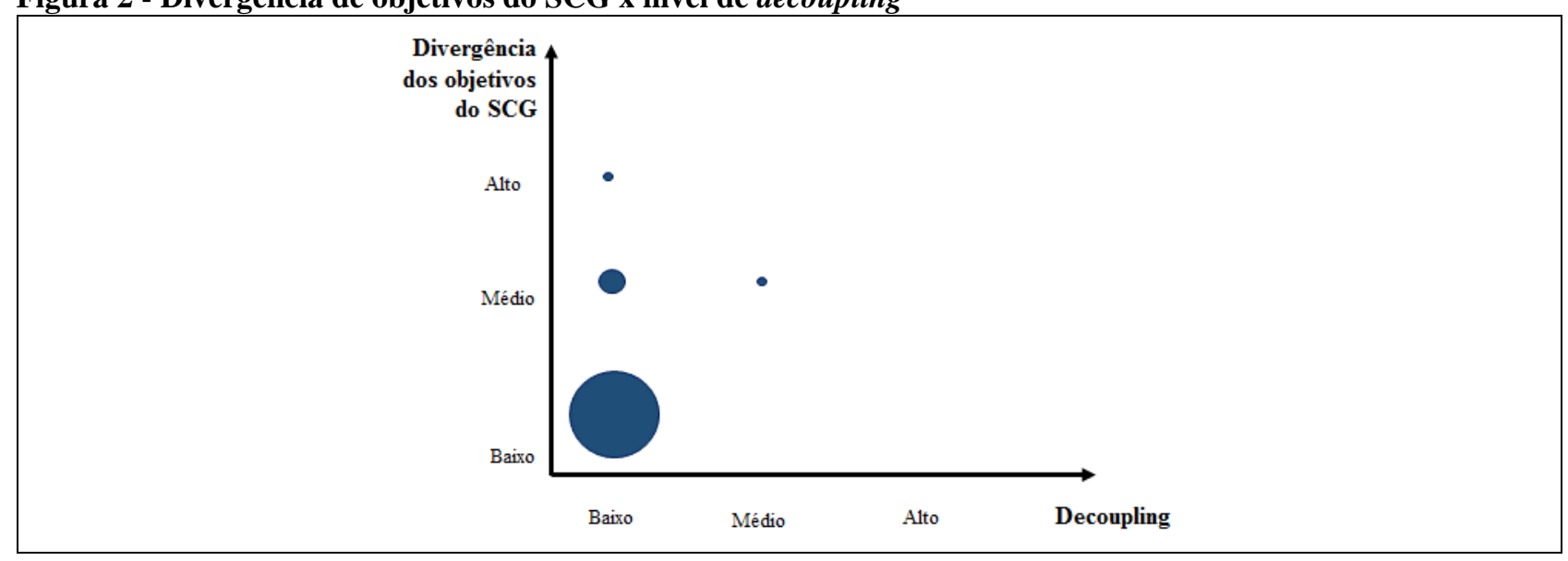

Fonte: elaborada pelos autores. 
A maioria das empresas da amostra, $74 \%$ das subsidiárias, se concentra no campo baixa divergência de objetivos do SCG e baixo decoupling; $15 \%$ da amostra possui divergência média e decoupling baixo; e 7\% das empresas evidenciam divergência alta e decoupling baixo. Observa-se que $4 \%$ da amostra apresentam divergência e decoupling médios. Essa análise demonstra que, nas subsidiárias com baixo nível de decoupling, há baixa divergência entre os objetivos do sistema de custos gerenciais, ou seja, quando as subsidiárias estão alinhadas com os objetivos determinados pela matriz, acabam por nortear os mesmos objetivos para TDL.

A última análise desenvolvida diz respeito à relação entre o grau de atingimento dos objetivos do sistema de custos (desempenho) e o nível de decoupling das práticas do sistema. A pressuposição inicial é que existe uma associação entre o atingimento dos objetivos do sistema com baixo nível de decoupling. O objetivo 'redução de custos' foi selecionado para esta análise, e a Figura 3 ilustra a relação entre desempenho do sistema gerencial de custos e o nível de decoupling.

Figura 3 Desempenho do SCG x Nível de decoupling

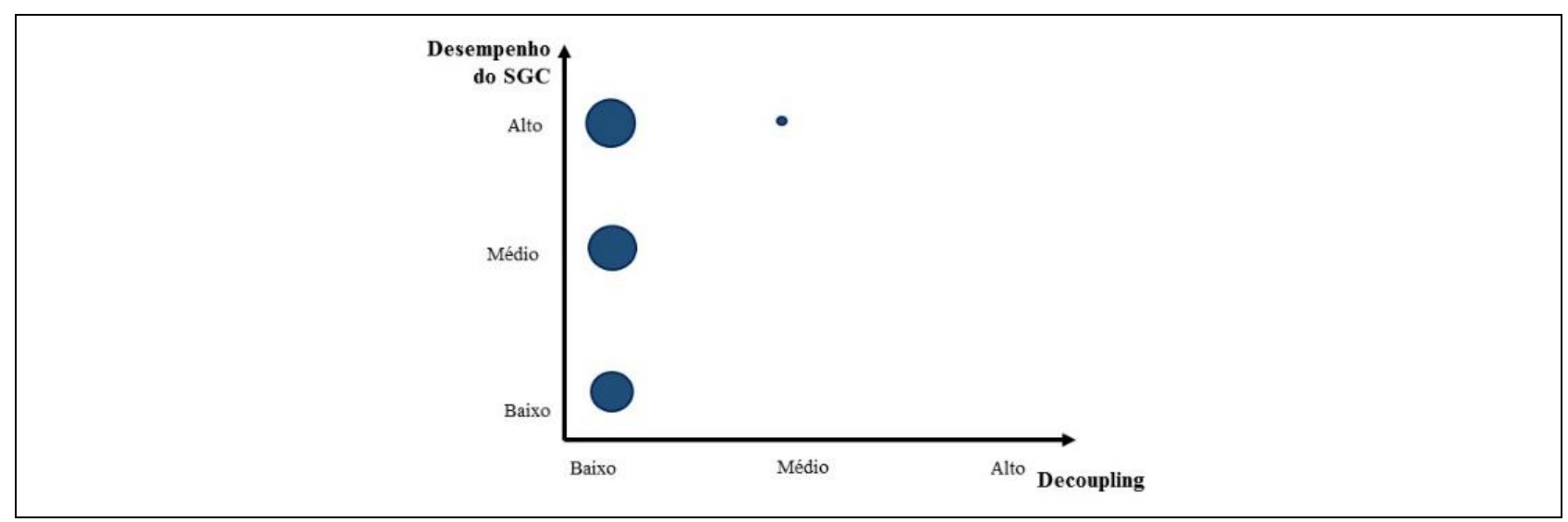

Fonte: elaborada pelos autores.

Os dados demonstram que em $37 \%$ da amostra estudada existe alto desempenho do sistema relacionado com o baixo nível de decoupling; em 33\% das empresas, o desempenho é classificado como médio e decoupling baixo; e, em $26 \%$, o desempenho é baixo com nível baixo de decoupling. Em síntese, os dados descritivos não permitem inferir que existe relação entre o atingimento desse objetivo do sistema de custos com o baixo nível de decoupling apresentado na amostra.

\section{CONSIDERAÇÕES FINAIS}

O objetivo geral do trabalho foi investigar as características institucionais do sistema de custos gerencial de subsidiária alemã operando no Brasil e avaliar se as práticas utilizadas por essas subsidiárias para tomada de decisão local são influenciadas pela matriz. A análise institucional foi desenvolvida considerando duas perspectivas: as pressões isomórficas de convergência - coercitivas, miméticas e normativas - e o decoupling no relacionamento entre matriz e subsidiária.

Considera-se que o objetivo geral da pesquisa foi atingido ao encontrar evidências, na amostra investigada, sobre a existência de forte associação entre a pressões isomórficas e o nível de decoupling. A pressão isomórfica coercitiva explica em grande parte a aderência (ausência de dissociação) entre as práticas para TDL e de reporte à matriz.

Os resultados demonstram também a presença de mimetismo nas características do sistema de custos gerenciais. As empresas da amostra possuem matriz do mesmo país de origem (Alemanha), atuam no mesmo local (Brasil) e pertencem ao mesmo ramo de atividade (automobilístico e máquinas e equipamentos). Esses fatores ajudam a explicar que determinadas práticas e ferramentas de gestão são utilizadas em função das pressões isomórficas miméticas. É importante observar que as características do sistema de custos gerencias são influenciadas simultaneamente por pressões 
institucionais em sua forma coercitiva e mimética, todavia, o instrumento desenvolvido na presente pesquisa não teve como propósito mensurar qual o tipo de pressão é mais marcante para moldar as características do sistema de custos gerenciais.

No que diz respeito às pressões isomórficas normativas, os resultados indicam que, embora existindo traços dessas pressões nas empresas estudadas, o seu nível pode ser considerado baixo.

Scott (2001) considera que a presença de pressões isomórficas em sua forma coercitiva contribui para a redução do nível de decoupling. Os resultados encontrados nesta pesquisa corroboram essa assertiva, pois foram encontradas correlações negativas entre a presença de isomorfismo coercitivo e o nível de decoupling das subsidiárias alemãs em relação à matriz. Além disso, os achados demonstram que a maioria das subsidiárias que possuem baixa divergência de objetivos do SCG entre matriz e TDL, também possuem baixo decoupling.

Com relação ao desempenho do sistema de gerenciamento de custo (grau de atingimento dos objetivos do sistema), os dados não permitem inferir sobre a existência de relação entre o atingimento de objetivos do sistema e o nível de decoupling. O principal objetivo do sistema de custos gerencial, declarado pelos participantes, foi 'redução de custos', todavia não foi possível observar se as empresas com baixo nível de decoupling atingem esse objetivo com maior frequência. Considera-se este achado interessante, pois traz indícios de que a aderência às práticas da matriz não necessariamente pode conduzir a subsidiária ao atingimento dos objetivos locais do sistema de custos gerencial.

O trabalho apresenta contribuições relevantes para o conhecimento da área, considerando três aspectos interligados, ou seja, estudo sobre subsidiárias alemãs operando no Brasil, características dos sistemas de custos gerenciais dessas empresas e a análise do isomorfismo e decoupling no âmbito do relacionamento subsidiária e matriz.

A principal limitação da pesquisa é que o universo de empresas estudado é reduzido, ou seja, ele é composto por 140 indústrias, porém, acredita-se que o estudo de setores específicos aumenta o nível de homogeneidade e comparabilidade entre os elementos da amostra. Entretanto, estudos futuros, que tenham como proposito realizar generalizações, poderiam analisar um universo mais diversificado de empresas subsidiárias, somente alemãs ou incluindo outras nacionalidades. Pesquisas futuras poderiam também estudar os elementos constitutivos das pressões isomórficas da matriz sobre empresas subsidiárias, com objetivo de avaliar qual tipo de pressão é mais marcante na determinação das características dos sistemas de custos gerenciais. Além disso, recomendam-se estudos longitudinais para melhor compreensão de mudanças nas relações e pressões exercidas na relação matriz e subsidiárias.

\section{REFERÊNCIAS}

Atkinson, A. A., Kaplan, R. S., \& Young, M. S. (2010). Contabilidade Gerencial. 2. ed. São Paulo: Atlas.

Barbosa, R. V. N., de Araújo Wanderley, C., \& de Moura Soeiro, T. (2017). Institucionalização dos mecanismos de controle gerencial no relacionamento interorganizacional de uma empresa do setor elétrico. Revista Universo Contábil, 13(3), 29-49.

Beuren, I. M., Fachini, G. J., \& do Nascimento, S. (2010). Evidências de isomorfismo nas funções da controladoria das empresas familiares têxteis de Santa Catarina. Revista Contemporânea de Contabilidade, 7(13), 35-62.

Björkman, I., Fey, C. F., \& Park, H. J. (2007). Institutional theory and MNC subsidiary HRM practices: evidence from a three-country study. Journal of International Business Studies, 38(3), 430-446.

Brandau, M., Endenich, C., Trapp, R., \& Hoffjan, A. (2013). Institutional drivers of conformity-Evidence for management accounting from Brazil and Germany. International Business Review, 22(2), 466-479.

Brown, R. S. (2011). Does institutional theory explain foreign location choices in fragmented industries?. Journal of International Business Research, 10(1), 59.

Bruns, W. J., \& Waterhouse, J. H. (1975). Budgetary control and organization structure. Journal of Accounting Research, 177-203. 
Callado, A. A. C., \& de Pinho, M. A. B. (2014). Evidências de isomorfismo mimético sobre práticas de gestão de custos entre micro e pequenas empresas de diferentes setores de atividade. Contabilidade Vista \& Revista, 25(2), 119-137.

Callado, A. A. C., Callado, A. L. C., \& Almeida, M. A. (2014). Isomorfismo e práticas de gestão de custos: um estudo empírico entre empresas do porto digital a partir da teoria institucional. Perspectivas em Gestão \& Conhecimento, 4(1), 204-217.

Câmara do Comércio e Indústria Brasil-Alemanha. (2019). Disponível em: http://www.ahkbrasilien.com.br/pt/. Acesso em: 2019.

Carruthers, B. G. (1995). Accounting, ambiguity, and the new institutionalism. Accounting, Organizations and Society, 20(4), 313-328.

Cohen, S., Kaimenaki, E., \& Zorgios, Y. (2007). Assessing IT as a key success factor for accrual accounting implementation in Greek municipalities. Financial Accountability \& Management, 23(1), 91-111.

Cruz, I., Major, M., \& Scapens, R. W. (2009). Institutionalization and practice variation in the management control of a global/local setting. Accounting, Auditing \& Accountability Journal, 22(1), 91-117.

DiMaggio, P., \& Powell, W. W. (1983). The iron cage revisited: Collective rationality and institutional isomorphism in organizational fields. American Sociological Review, 48(2), 147-160.

Dorminey, J., Fleming, A. S., Kranacher, M. J., \& Riley Jr, R. A. (2012). The evolution of fraud theory. Issues in Accounting Education, 27(2), 555-579.

Endenich, C., Brandau, M., \& Hoffjan, A. (2011). Two decades of research on comparative management accounting-achievements and future directions. Australian Accounting Review, 21(4), 365-382.

Fávero, L. P., Belfiore, P., Silva, F. D., \& Chan, B. L. (2009). Análise de Dados: modelagem multivariada para tomada de decisões. Rio de janeiro: Elsevier.

Fonseca, V. S. D., \& Machado-da-Silva, C. L. (2010). Conversação entre abordagens da estratégia em organizações: escolha estratégica, cognição e instituição. Revista de Administração Contemporânea, 14(SPE), 51-75.

Frezatti, F. (2005). Management accounting profile of firms located in Brazil: a field study. Revista de Administração Contemporânea, 9(SPE2), 95-109.

Friedl, G., Küpper, H. U., \& Pedell, B. (2005). Relevance added: Combining ABC with German cost accounting. Strategic Finance, 86(12), 56.

Gosselin, M. (2006). A review of activity-based costing: technique, implementation, and consequences. Handbooks of Management Accounting Research, 2, 641-671.

Guerreiro, R., Cornachione Júnior, E. B., \& Soutes, D. O. (2011). Empresas que se destacam pela qualidade das informações a seus usuários externos também se destacam pela utilização de artefatos modernos de contabilidade gerencial?. Revista Contabilidade \& Finanças, 22(55), 88-113.

Guerreiro, R., Pereira, C. A., \& Frezatti, F. (2006). Evaluating management accounting change according to the institutional theory approach. Journal of Accounting \& Organizational Change, 2(3), 196-228.

Guerreiro, R., \& Rocha, W. (2010). Desenvolvimento de modelo conceitual de sistemas de custos: um enfoque institucional. Revista de Contabilidade e Organizações, 4(8), 24-46.

Guerreiro, R., \& Souza, R. P. (2015). Um estudo sobre percepções de importância de atividades do processo de gestão e barreiras à implantação do planejamento estratégico. Revista Universo Contábil, 11(1), 88104.

Guilding, C., Cravens, K. S., \& Tayles, M. (2000). An international comparison of strategic management accounting practices. Management Accounting Research, 11(1), 113-135.

Haveman, H. A. (1993). Follow the leader: Mimetic isomorphism and entry into new markets. Administrative Science Quarterly, 38(4), 593-627.

Hughes, S. B., \& Paulson Gjerde, K. A. (2003). Do different cost systems make a difference?. Management Accounting Quarterly, 5(1), 22-30.

Kajüter, P. (2005). Kostenmanagement in der deutschen Unternehmenspraxis. Schmalenbachs Zeitschrift für betriebswirtschaftliche Forschung, 57(1), 79-100.

Kajüter, P., \& Schröder, M. (2013). The characteristics, determinants and performance of cost-systems in sub-sidiaries of Anglophone multinationals-empirical evidence from Germany (Doctoral dissertation, Doctoral Thesis).

Kellermanns, F. W., \& Islam, M. (2004). US and German Activity-Based Costing: a critical comparison and system acceptability propositions. Benchmarking: An International Journal, 11(1), 31-51. 
Krumwiede, K., \& Suessmair, A. (2008). A Closer Look at German Cost Accounting Methods. Management accounting quarterly, 10(1), 37-50.

Krumwiede, K. R. (1998). The implementation stages of activity-based costing and the impact of contextual and organizational factors. Journal of management accounting research, 10(1), 239.

Major, M., \& Hopper, T. (2005). Managers divided: Implementing ABC in a Portuguese telecommunications company. Management Accounting Research, 16(2), 205-229.

Marques, K. C. M. (2012). Custeio alvo à luz da teoria da contingência e da nova sociologia institucional: estudo de caso sobre sua adoção, implementação e uso (Doctoral Dissertation, Universidade de São Paulo).

Meyer, J. W., \& Rowan, B. (1977). Institutionalized organizations: Formal structure as myth and ceremony. American Journal of Sociology, 83(2), 340-363.

Mizruchi, M. S., \& Fein, L. C. (1999). The social construction of organizational knowledge: A study of the uses of coercive, mimetic, and normative isomorphism. Administrative Science Quarterly, 44(4), 653683.

Moll, J., Burns, J., \& Major, M. (2006). Institutional theory. Methodological issues in accounting research: Theories, methods and issues, 183-205.

Ono, K., \& Robles Junior, A. (2004). Utilização do Target Costing e de outras técnicas de custeio: um estudo exploratório em municípios de Santa Catarina. Revista Contabilidade \& Finanças, 15(SPE), 65-78.

Oyadomari, J. C., Cardoso, R. L., NETO, O. R. D. M., \& de Lima, M. P. (2008). Fatores que influenciam a adoção de artefatos de controle gerencial nas empresas brasileiras. Um estudo exploratório sob a ótica da teoria institucional. Revista de Contabilidade e Organizações, 2(2), 55-70.

Oyadomari, J. C. T., de Mendonça Neto, O. R., Cardoso, R. L., \& Frezatti, F. (2008). Análise dos fatores que favorecem a institucionalização da Value Based Management (VBM) à luz dos argumentos de teóricos da vertente New Institutional Sociology (NIS). Revista Universo Contábil, 4(2), 06-21.

Perrow, C., Meyer, J. W., \& Scott, W. R. (1983). Organizational environments: Ritual and rationality. (With the assistance of Brian Rowan and Terrence E. Deal.). Beverly Hills, Calif.: Sage Publications.

Portz, K., \& Lere, J. C. (2010). Cost center practices in Germany and the United States: impact of country differences on managerial accounting practices. American Journal of Business, 25(1), 45-52.

Reginato, L., \& Guerreiro, R. (2011). An Study About The Association Between The Management Model And Management Controls Of Brazilian Industries. Revista Universo Contabil, 7(2), 6-27.

Russo, P. T., \& Guerreiro, R. (2017). Factors that affect the sociomateriality of management accounting practices. Annual Congress of European Accounting Association, Valencia, Espanha.

Russo, P. T., \& Guerreiro, R. (2017). Perceptions about the sociomateriality of management accounting practices. Revista de Administração de Empresas, 57(6), 567-584.

Rezende, A. J., Guerreiro, R., \& Dalmácio, F. Z. (2012). Uma análise do processo de desinstitucionalização de práticas contábeis de correção monetária em empresas brasileiras. Revista Contabilidade \& Finanças, 23(58), 33-51.

Salancik, G. R., \& Pfeffer, J. (1978). A social information processing approach to job attitudes and task design. Administrative Science Quarterly, 224-253.

Scott, W. R. (2008). Approaching adulthood: the maturing of institutional theory. Theory and Society, 37(5), 427.

Scott, W. R. (2001). Institutions and organizations. Sage.

Shields, M. D. (1998). Management accounting practices in Europe: a perspective from the States. Management Accounting Research, 9(4), 501-513.

Siti-Nabiha, A. K., \& Scapens, R. W. (2005). Stability and change: an institutionalist study of management accounting change. Accounting, Auditing \& Accountability Journal, 18(1), 44-73.

Smith, M. (2003). Research Methods In Accounting. Sage.

Souza, M. A. D., Lisboa, L. P., \& Rocha, W. (2003). Práticas de contabilidade gerencial adotadas por subsidiárias brasileiras de empresas multinacionais. Revista Contabilidade \& Finanças, 14(32), 40-57.

Souza, M. A., Silva, É. J., \& Pilz, N. (2010). Práticas de gestão estratégica de custos: um estudo em uma empresa multinacional brasileira. Revista de Contabilidade e Organizações, 4(9), 145-167.

Sulaiman, M., Ahmad, N. N. N., \& Alwi, N. (2004). Management accounting practices in selected Asian countries: a review of the literature. Managerial Auditing Journal, 19(4), 493-508. 
Van der Stede, W. A. (2003). The effect of national culture on management control and incentive system design in multi-business firms: evidence of intracorporate isomorphism. European Accounting Review, 12(2), 263-285.

Van der Stede, W. A., Young, S. M., \& Chen, C. X. (2005). Assessing the quality of evidence in empirical management accounting research: The case of survey studies. Accounting, Organizations and Society, 30(7-8), 655-684.

Wegmann, G. et al. (2008). The activity-based costing method developments: state-of-the art and case study. ICFAI-University Journal of Accounting Research, 1-17.

Wegmann, G., Nozile, S. (2009). The Activity-Based Costing Method developments: state-of-the art and case study in the it supply chain of an international group. International Conference On Information And Management Sciences, 7, Proceedings.

Yazdifar, H., Zaman, M., Tsamenyi, M., \& Askarany, D. (2008). Management accounting change in a subsidiary organisation. Critical Perspectives on Accounting, 19(3), 404-430. 